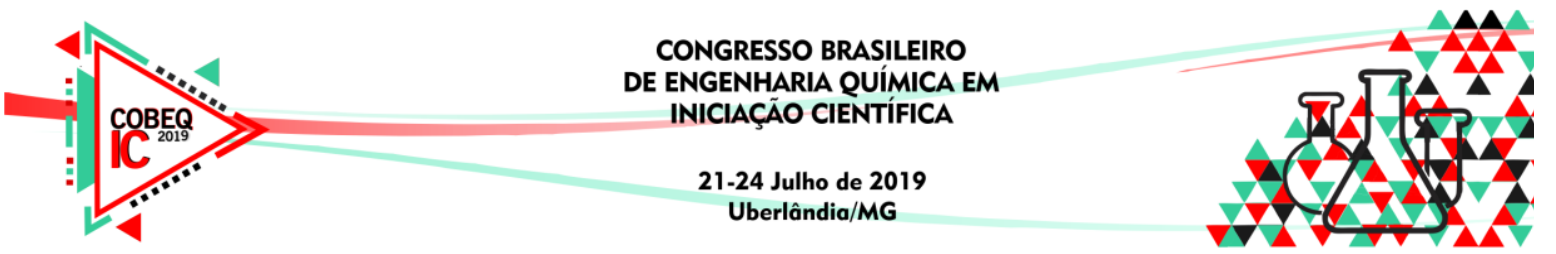

\title{
AVALIAÇÃO DA INFLUÊNCIA DE DIFERENTES SOLVENTES NA EXTRAÇÃO DE ANIBA CANELILLA
}

\author{
I. D. GIROLDO ${ }^{1}$, L. A. CAVALCANTE ${ }^{1}$, M. L. F. $\operatorname{SALES}^{1}$, L. M. BASTOS ${ }^{2}$, M. P. S. \\ SOUSA $^{1}$ \\ ${ }^{1}$ Universidade Federal Do Amazonas, Faculdade de Engenharia Química \\ ${ }^{2}$ Universidade Federal Do Amazonas, Faculdade de Farmácia \\ E-mail para contato: izabeladamasg@gmail.com
}

\begin{abstract}
RESUMO - A Aniba canelilla é da família Lauracea e tem como nome popular preciosa, é muito usada na medicina popular para catarro crônico, resfriado, febres, além de ser do interesse da indústria de cosméticos. Tem como composto majoritário o 1-nitro-2-feniletano, além de ter também metileugenol, eugenol. As plantas aromáticas, por possuírem flavonoides e compostos fenólicos tem capacidade antioxidante. Assim, a Aniba canelilla apresenta potencial capacidade antioxidante. Neste estudo foi feito a avaliação a influência do solvente nos extratos das folhas levando em consideração seu rendimento e sua capacidade antioxidante. Fez-se extratos etanólico, extratos hidroalcoólico, extrato aquoso (com folhas secas a temperatura ambiente e secas na estufa), óleo essenciais (com folhas secas a temperatura ambiente e secas na estufa). Os testes a determinação de fenólicos totais e DPPH para determinar a capacidade antioxidante foram positivos, com destaque ao extrato aquoso, seguido do extrato etanólico.
\end{abstract}

\section{INTRODUÇÃO}

No Brasil já foram realizadas campanhas nacionais para que o conhecimento tradicional seja reconhecido pelo Ministério da saúde, devido a sua grande efetividade no tratamento de doenças. Dentre essas espécies, a A. canelilla, conhecida como preciosa é nativa da Amazônia, pertencendo a família Lauracea (Lupe, 2007). A espécie é abundantemente utilizada na medicina popular contra esgotamento nervoso e artritismo. O chá das folhas e a casca são usadas para tratar resfriados, febres, náuseas, catarro crônico, sífilis, dores de cabeça e vários tipos de infecção. É considerado antianêmico, antidesentérico, antiespasmódico e digestivo (Cristina et al., 2016). O óleo essencial é usado contra acnes, dermatites, febre, infecções diversas e ferimentos e possuem como composto majoritário o 1-nitro-2-feniletano, derivada da fenilalanina (Lupe, 2007), além de conter sesquiterpenos, benzenoides como metileugenol, eugenol. Segundo Barbosa (2016), 1-nitro-2-feniletano foi significativamente maior no óleo essencial dos ramos. Já o óleo essencial das folhas apresentou maior quantidade de eugenol e metileugenol.

Um grande número de plantas aromáticas tem propriedades antioxidantes, e estes efeitos devem-se principalmente aos compostos fenólicos, tais como flavonoides, ácidos fenólicos e diterpenos fenólicos (Miliauskas et al., 2004, citado por Silva, 2012). Portanto, a espécie A. canelilla apresenta potencial como fonte de novos compostos antioxidante. Porém, não é possível escolher uma metodologia dada como mais eficiente para extração de compostos 


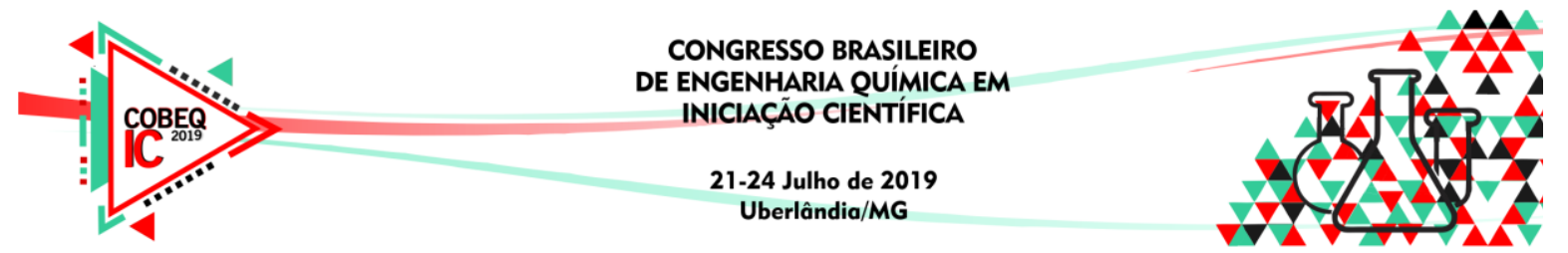

antioxidantes que sofrem influencia de diversos fatores. Esses fatores podem ser o método, tempo e temperatura de extração, o solvente usado e a natureza das móleculas (Andreo e Jorge, 2006). Seu rendimento também pode ser afetados pelas condições citadas.

A oxidação faz parte de processos que ocorrem no organismo humano, porém a oxidação incompleta é capaz de produzir espécies reativas de oxigênio ou radicais livres, prejudiciais ao organismo. A quantidade desses radicais é controlada por antioxidantes, que são encontrados em alimentos, cosméticos e no próprio corpo (Mesquita et al., 2014). Para verificar o teor de compostos fenólicos totais que são antioxidantes, utiliza-se do método espectrofotométrico de Folin-Ciocalteau utilizando ácido gálico (AG) como padrão de referência (Federal, Anal e Bastos, 2019). Para verificar o potencial antioxidante in vitro de extratos e/ou substâncias isoladas faz-se o método de sequestro do radical livre DPPH (2,2 difenil-1-picril-hidrazil), tendo como referência o ac. gálico (Federal e Anal, 2019).

A solubilidade de uma substância orgânica é relacionada com a estrutura molecular, com a polaridade das ligações e da espécie química como um todo. Geralmente, os compostos apolares são solúveis em solventes apolares e compostos de alta polaridade são solúveis em solventes também polares, concordando com a regra empírica de grande utilidade: "polar dissolve polar, apolar dissolve apolar"(Martins, Araújo e Bittencourt, 2013).

\section{MATERIAIS E MÉTODOS}

\subsection{Material Vegetal}

As folhas e galhos da A. canelilla foram coletados na mata da Universidade Federal do Amazonas. As folhas foram trituradas e secas de duas formas diferentes: (i) em estufa a $45^{\circ} \mathrm{C}$; (ii) à temperatura ambiente $\left(27 \pm 1^{\circ} \mathrm{C}\right)$.

\subsection{Preparo da Amostra}

Extrato etanólico e hidroalcoólico: o extrato etanólico foi obtido a partir de $20 \mathrm{~g}$ folhas secas a temperatura ambiente e moídas utilizando como solvente $50 \mathrm{~mL}$ de álcool etílico, usando a técnica de macereção, por 3 ciclos de 72 horas, em cada ciclo, o extrato era rotaevaporado e então seco em capela. Depois disso, continuou a extração utilizando como solvente uma mistura de água e etanol,numa proporção de $50 \mathrm{ml}$ de etanol e $150 \mathrm{ml}$ de água destilada, obtendo portanto, o extrato hidroalcoólico que posteriormente foi rotaevaporado e liofilizado.

Extrato aquoso: foram obtidos de $50 \mathrm{~g}$ de folhas seca na estufa e de folha secas em temperatura ambiente, ambas moídas e submetidos à fervura para a obtenção de um chá similarmente como é feito pela população. Após esse processo, os extratos foram liofilizados.

Óleo essencial: foram obtidos através das folhas da estufa e folhas secas em temperatura ambiente, com $100 \mathrm{~g}$ de folhas, destilados com 1L de água cada no aparelho Clevenger. 


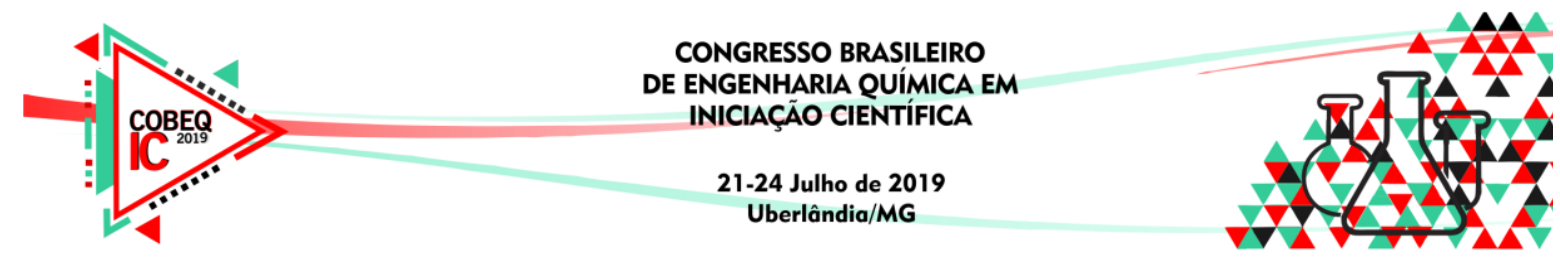

\subsection{Teste de DPPH}

A análise de DPPH foi feita no Laboratório de Abertura de Amostras e Ensaios Químicos (LAEQ) da UFAM. As amostras para análise (extratos/frações/padrões) foram solubilizadas em metanol (grau HPLC) na concentração de $1,0 \mathrm{mg} / \mathrm{mL}$. O ensaio foi realizado em microplacas de 96 poços, onde adicionou-se $30 \mu \mathrm{L}$ das amostras em triplicata e em seguida adicionou-se $30 \mu \mathrm{l}$ do metanol. Foram realizadas sucessivas diluições em ordem decrescente $(100 ; 5 ; 2,5 ; 1,25 ; 0,62$ e 0,$31 ; 0,15$ e $0,07 \mu \mathrm{g} / \mathrm{mL})$. A seguir foram adicionados $270 \mu \mathrm{L}$ de DPPH $100 \mu \mathrm{M}$ em cada poço. Aguardou-se 30 minutos, mantendo a microplaca protegida da luz direta. Foi utilizado metanol (grau HPLC), como branco e a solução de DPPH, como controle negativo. A leitura da absorbância foi realizada em leitor de absorbância em microplacas ELx808 ${ }^{\mathrm{TM}}$, no comprimento de onda de $515 \mathrm{~nm}$. A capacidade antioxidante medida é expressa pela concentração da amostra $(\mu \mathrm{g} / \mathrm{mL})$ capaz de sequestrar $50 \%$ dos radicais livres de DPPH (EC50) pela atividade antioxidante, conforme equação (1). Onde AA\% representa atividade antioxidante, Absamostra representa a absorbância da amostra, Absbranco representa a absorbância do branco (metanol) e Abscontrole representa a absorbância do controle (solução de DPPH).

$\mathrm{AA} \%=100-\left\{\left[\left(\mathrm{Abs}_{\text {amostra }}-\mathrm{AbS}_{\text {branco }}\right) \mathrm{x} 100\right] / \mathrm{Abs}_{\text {controle }}\right\}$

Onde AA\% representa atividade antioxidante, Absamostra representa a absorbância da amostra, Abs branco representa a absorbância do branco (metanol) e Abs controle representa a absorbância do controle (solução de DPPH).

\subsection{Análise de Fenólicos Totais}

As amostras foram preparadas seguindo a mesma metodologia do DPPH. A análise foi realizada também em microplacas de 96 poços e para o preparo da curva analítica do padrão foram adicionados $20 \mu \mathrm{L}$ do padrão ácido gálico (solução mãe), em seguida adicionou-se 20 $\mu \mathrm{L}$ de metanol (grau HPLC) e retirou-se $20 \mu \mathrm{L}$ do primeiro poço, realizando-se sucessivas diluições. A seguir foram adicionados $150 \mu \mathrm{L}$ de solução Folin Ciocalteau 10\%. Passados 5 minutos, adicionou-se ao meio $150 \mu \mathrm{L}$ de solução $\mathrm{NaHCO}_{3}(6 \%)$. Aguardou-se 90 minutos para a leitura do meio no comprimento de onda de $750 \mathrm{~nm}$ em leitor de multiplacas de absorbância ELX 808. A presença de substâncias fenólicas na amostra será detectada pela conversão da coloração amarela do meio racional para a coloração azul. Os resultados da concentração de fenólicos totais foram expressos em miligramas de equivalentes do padrão ácido gálico, ou seja, um resultado positivo se aproxima de 1 miligrama de equivalentes de ác. gálico.

\section{RESULTADOS E DISCUSSÃO}




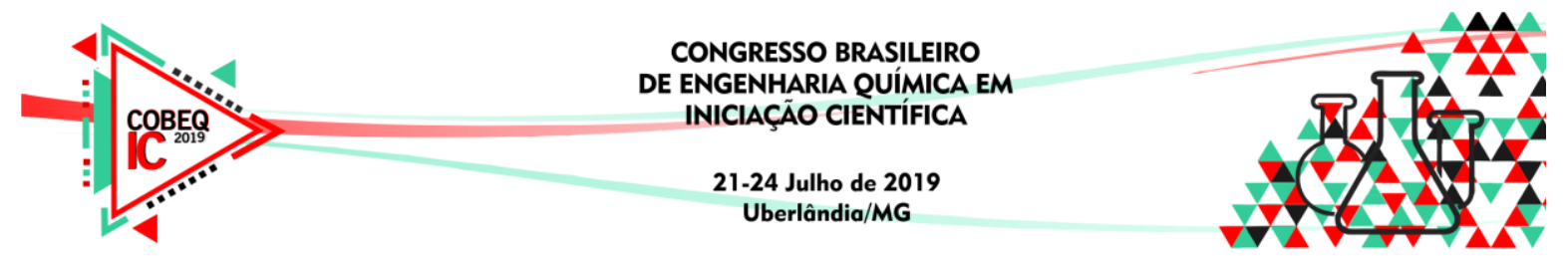

\subsection{Rendimento das amostras}

A tabela 1 apresenta os rendimentos dos diferentes extratos e do óleo essencial das diferentes amostras.

Tabela 1- Rendimento (\%) das amostras após as extrações das folhas.

\begin{tabular}{|c|c|}
\hline Amostras & Rendimento (\%) \\
\hline Extrato Hidroalcoólico & 6,6 \\
\hline Extrato Etanólico & 18,9 \\
\hline Extrato Aquoso com folhas secas na estufa & 0,8 \\
\hline Extrato Aquoso com folhas secas a temperatura ambiente. & 0,8 \\
\hline Óleo Essencial com folhas secas na estufa & 0,6 \\
\hline Óleo Essencial com folhas secas a temperatura ambiente & 2,7 \\
\hline
\end{tabular}

Como pode ser visto na tabela 1 , o método de maceração com etanol apresentou maior rendimento, muito provavelmente pela similaridade entre a matriz e o solvente. $\mathrm{O}$ extrato hidroalcoólico possuiu o segundo melhor rendimento, por se tratar de um solvente mais polar foi capaz de extrair substâncias mais polares que ainda não havia sido arrastada pelo solvente menor polaridade. O óleo essencial das folhas secas na estufa apresentou o menor rendimento entre as amostras, pois os óleos essenciais são frações voláteis naturais, extraídas de plantas aromáticas que evaporam à temperatura ambiente (Santos et al., 2004). Por estarem na estufa a temperatura de $40{ }^{\circ} \mathrm{C}$, componentes do óleo podem ter evaporado.

\subsection{Resultado do Teste de Fenólicos Totais e Análise de DPPH}

A tabela 2 mostra os resultados de fenólicos totais para as amostras analisadas. O resultado mais expressivo foi do extrato aquoso das folhas secas em temperatura ambiente, que foi melhor que o padrão como pode ser analisado na tabela 2.

Tabela 2 - Resultado de fenólicos totais pelo método Folin-Ciocalteau

$\left.\begin{array}{|c|c|}\hline \text { Amostras } & \begin{array}{c}\text { Fenólicos totais } \\ \text { (mg EAG.g }\end{array} \\ \hline \text { Extrato Hidroalcoólico }\end{array}\right)$

Sendo mg EAG.g ${ }^{-1}$ : miligrama equivalente de Ácido gálico.

O resultado da análise DPPH pode ser consultada na tabela 3. 


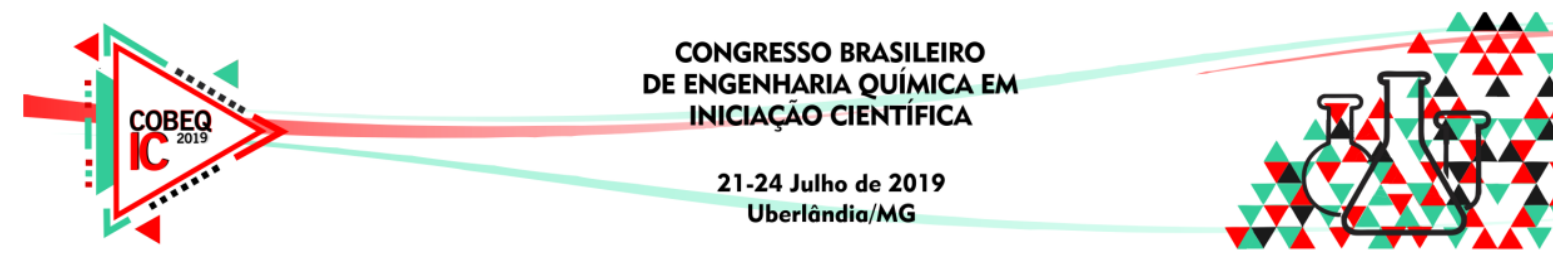

Tabela 3 - Porcentagem da atividade antioxidante

\begin{tabular}{|c|c|}
\hline Amostras & \%AA \\
\hline Extrato Hidroalcoólico & 86,5 \\
\hline Extrato Etanólico & 93,3 \\
\hline Extrato Aquoso com folhas secas na estufa & 93,1 \\
\hline Extrato Aquoso com folhas secas a temperatura ambiente. & 97,8 \\
\hline
\end{tabular}

Sendo \%AA: porcentagem de atividade antioxidante.

Novamente, o melhor resultado foi do extrato aquoso das folhas secas na temperatura ambiente, seguido do extrato etanólico. Como foi possível observar, o extrato aquoso apresentou maior concentração de fenólicos totais e maior porcentagem de capacidade antioxidante. Isso mostra que a maior parte dos componentes fenólicos da $A$. canelilla são muito polares e a água, solvente muito polar, foi capaz de extrair esses compostos que são antioxidantes, seguido do extrato etanólico, que apesar de ter conseguido extrair menos compostos fenólicos que a amostra hidroalcoólica, os compostos que capturou apresentam uma capacidade antioxidante maior que o extrato hidroalcoólico. Isso indica que o solvente e a polaridade podem afetar o aspecto-chave na extração de polifenóis e consequentemente na capacidade antioxidante (Oliveira et al., 2017).

$\mathrm{Na}$ pesquisa realizada, não foram encontrados dados referentes à avaliação de antioxidantes do extrato aquoso, contudo, o extrato etanólico possui grande capacidade antioxidante, como corrobora Mesquita (2014), assim como os óleos essenciais contém moléculas com atividade antioxidante (Silva, 2012). Sendo assim, tem-se um resultado preliminar de que o extrato aquoso tem um potencial antioxidante significativo.

\section{CONCLUSÃO}

Neste trabalho foram avaliados o efeito no teor de fenólicos totais e na capacidade de extratos de Aniba canelilla devido ao emprego de diferentes solventes na extração e do método de extração. $\mathrm{O}$ extrato etanólico apresentou o maior rendimento dentre as amostras, por ser capaz de extrair uma maior quantidade de substâncias das folhas. O extrato aquoso com folhas secas à temperatura ambiente apresentou a maior capacidade antioxidante entre as amostras.

\section{REFERÊNCIAS}

ANDREO, D.; JORGE, N. Antioxidantes naturais: técnicas de extração. p. 319336, 2006.

BARBOSA, P. C. S.; FERNANDES, K. S.; MANHÃES, A. P.; CARNEIRO, S. B.; SAMPAIO, P. T. B.; WIEDEMANN, L. S. M.; JUNIOR, V. F. V. New and sustainable essential oils obtained from the long-term explored cinnamomum-like Aniba canelilla. Journal of Applied Research on Medicinal and Aromatic Plants, p. 1-12, 2016.

FEDERAL, U.; ANAL, A. C. Universidade Federal do Amazonas Central Analítica Relatório do potencial antioxidante pelo método de DPPH. 2019. 


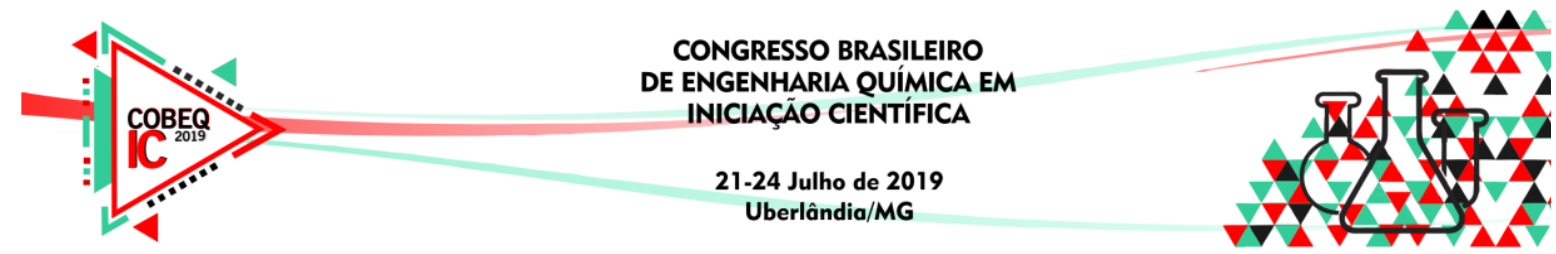

FEDERAL, U.; ANAL, A. C.; BASTOS, M. Relatório análise do conteúdo de fenólicos totais. 2019.

LUPE, F. A. Estudo da composição química de óleos essenciais de plantas aromáticas da amazônia.CAMPINAS, 2007.

MARTINS, C. R.; ARAÚJO, W.; BITTENCOURT, J. Quim. Nova,. v. 36, n. 8, p. 1248-1255, 2013.

MESQUITA, T. J. B.; SILVA, G. F.; ALBUQUERQUE, P. M.; JR, S. DUVOISIN. Análise Fitoquímica de Determinação da Capacidade Antioxidante em Extratos de Aniba canelilla (H.B.K.) MEZ. '1, p. 1-8, 2014.

OLIVEIRA, V. B.; DUARTE, A.; PAULA, C. D. S.; MIGUEL, M. D. Efeito de diferentes técnicas extrativas no rendimento, atividade antioxidante, doseamentos totais e no perfil por clae-dad de dicksonia sellowiana n. January 2016, 2017.

SANTOS, A. S.; ALVES, S. D. M.; FIGUEIRÊDO, F. J. C.; NETO, O. G. D. R. Descrição de Sis. e de Métodos de Extração de Ó. Essenciais e Det. de Umidade de Biomassa em Laboratório. n. 91, p. 1-6, 2004.

SILVA, G. F. DA. Estudo do Potencial Biotecnológico de Aniba canelilla (H.B.K) MEZ Para Obtenção de Cosméticos. [s.l.] Universidade do Estado do Amazonas (UEA), 2012. 